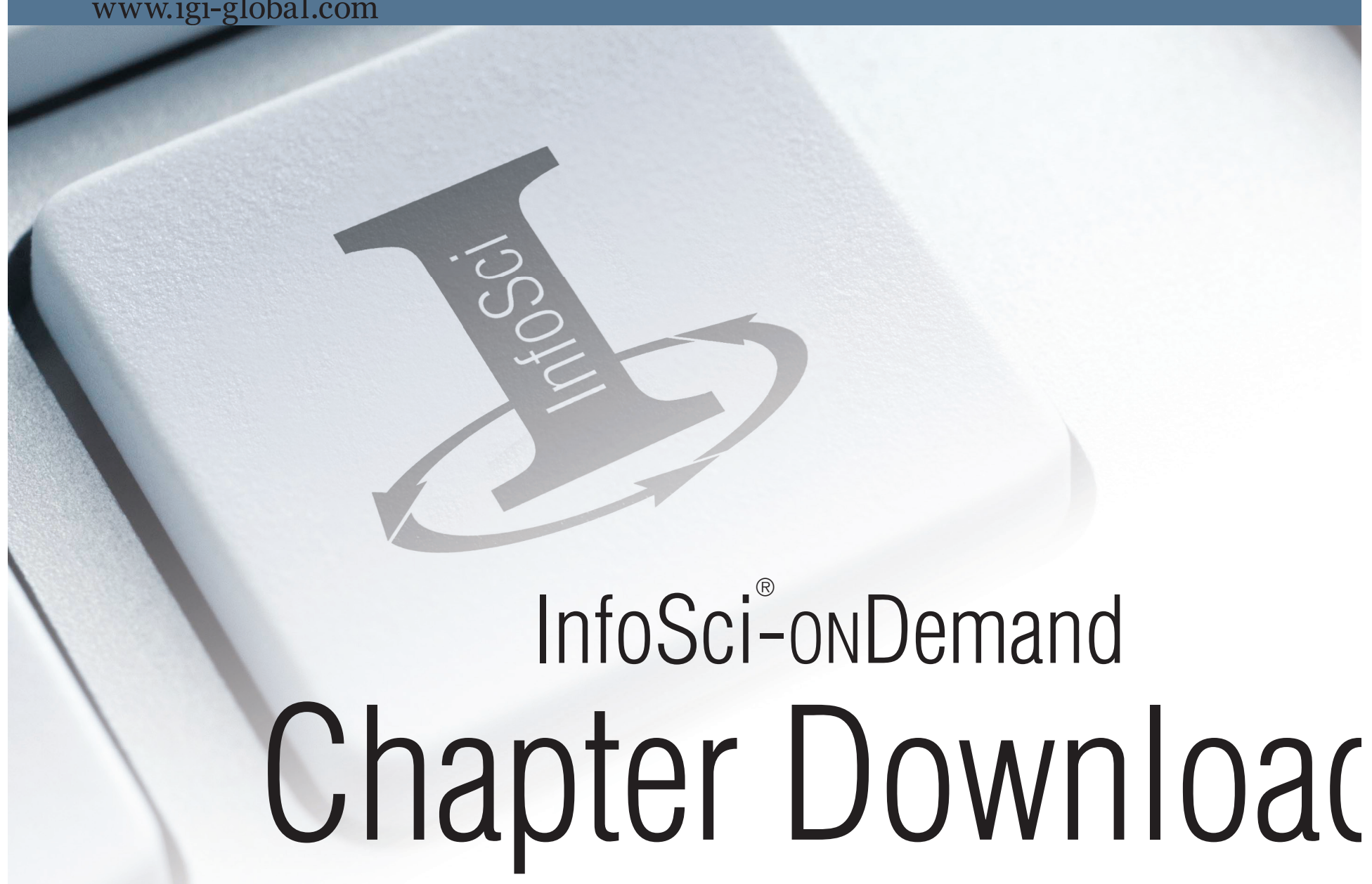
teaching cases from IGI Global's entire sel www.igi-global.com/ondemand

This publication is protected by copyright law of the United States of America codified in Title 17 of the U.S. Code, $v$ both the Universal Copyright Convention and the Berne Copyright Convention. The entire content is copyrighted All rights reserved. No part of this publication may be reproduced, posted online, stored, translated or distributed by any means without written permission from the publisher. 


\title{
Chapter 8 \\ A New Tool for Supporting Innovation in Biotech Co-Innovation and the Role of Economic Developers
}

\author{
Marina Frangioni \\ Bishop's University, Canada
}

\section{ABSTRACT}

Biotech companies have been perceived has the Saint-Graal for economic development since a few years. But the economic downturn and a misunderstanding of the shift in innovation process, from a stage gate process to a user driven process placed, impairs biotech companies. Economic developer, which aims is to foster innovation to induce economic development asked themselves how to help innovation in the biotech sector to reach the market more rapidly and more efficiently. This book chapter present an overview in the innovation shift from the supply side to the demand side and propose a new model of intervention for economic developers in this new context of co-innovation. 


\section{A New Tool for Supporting Innovation in Biotech Co-Innovation INTRODUCTION}

Since the last 50 years, innovation has been perceived as a stage gate process involving university and manufacturers. A lot of effort has been made to support technology transfer from research centers to companies to market. In the meantime, Porter (1998) has developed his now renowned concept of clusters. Cities all around the world have put in place innovation strategies consistent with the geographic concentration of firms in selected industrial sectors. Montreal was no exception and the biotech cluster was one of the first, which has been brought to life back in the 00. InVivo (the cluster's Administration) is now at the crossroads and tries to help manufacturers and entrepreneurs to build a new pipeline of products and energize a new round of development. In history then, most of public policies and support was designed to help manufacturer in capturing innovation coming from research lab. But, many sociologists have stressed the importance of the network and the social fabric and users for the diffusion and the acceptance of innovation through society.

Despite this researches at the academic level, few works has been done to integrated, in one hand this new source of innovation (users) in the toolbox of economic developers and, in the other hand to understand and structure the demand side to foster innovation.

\section{BACKGROUND}

\section{Main Focus of the Chapter}

The aim of this paper is to see how the rules have changed for economic developers and how a new model can be proposed to help them to enrich their action towards entrepreneurs and business community. Moreover, this paper will study in the biotech sector how this proposed model could be implement.

\section{Innovation Evolution: A Quick Overview}

Innovation is recognized as the engine of economic and society development. In the early work of economists, it was identified mostly as technological progress. The seminal work of Schumpeter, demonstrated the importance of economic actor such as innovator (manufacturer and entrepreneur) in the technological progress and its way to transform society (destructive creation). Bust mostly of these works are based on a linear view of innovation.

In recent years, new perspectives on innovation are emerging. This is called «the demand side of innovation». It is based on the idea that users and communities 
Figure 1. Two perspectives on innovation

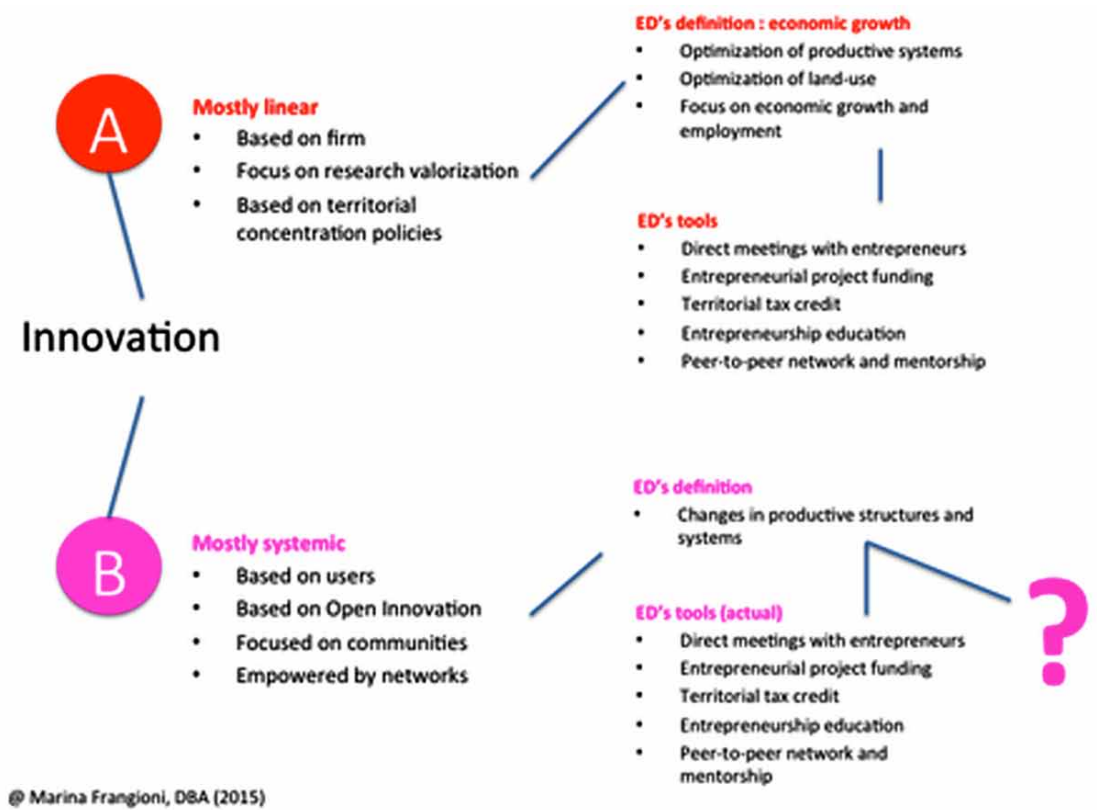

can be more then helpful in nurturing innovation process. The work of Von Hippel $(1986,2005)$ on lead users intervenes in the definition of the demand side innovation process, as well as work on network (Lemieux, 1976; Granovetter, 1978; Burt \& Celotto, 1992; Cohendet, Roberts \& Simon, 2010; Lemieux \& Ouimet, 2006).

Most of authors or practitioners tend to oppose those two perspectives. But it must be sees as the two sides of the same coin. In that perspective Figure 1 tends to give a quick overview of the two side of innovation process.

The first one, called the A perspective is mostly based on a linear view on innovation. In this perspective, the focus is clearly on the firm as the engine for economic growth and development.

Since 30 years, innovation has been perceived as a stage gate process involving universities and manufacturers. The main idea is to accelerate the commercialization between the bench and the market.

In this attempt to support innovation process and due out commercialization, strategies are deeply rooted in a linear vision of innovation (Von Hippel, 2005). The supply side of innovation, coming from labs and manufacturers, are at the core of innovation strategies, in order to increase the number of patents, commercialization and competitive advantage.

Thus, a lot of effort has been made to support technology transfer from research centers to companies and to market. In Quebec, with those kinds of strategies in mind, Valorisation Recherche Québec was created in the 90' and has funded several 
Figure 2. Innovation: A complex process

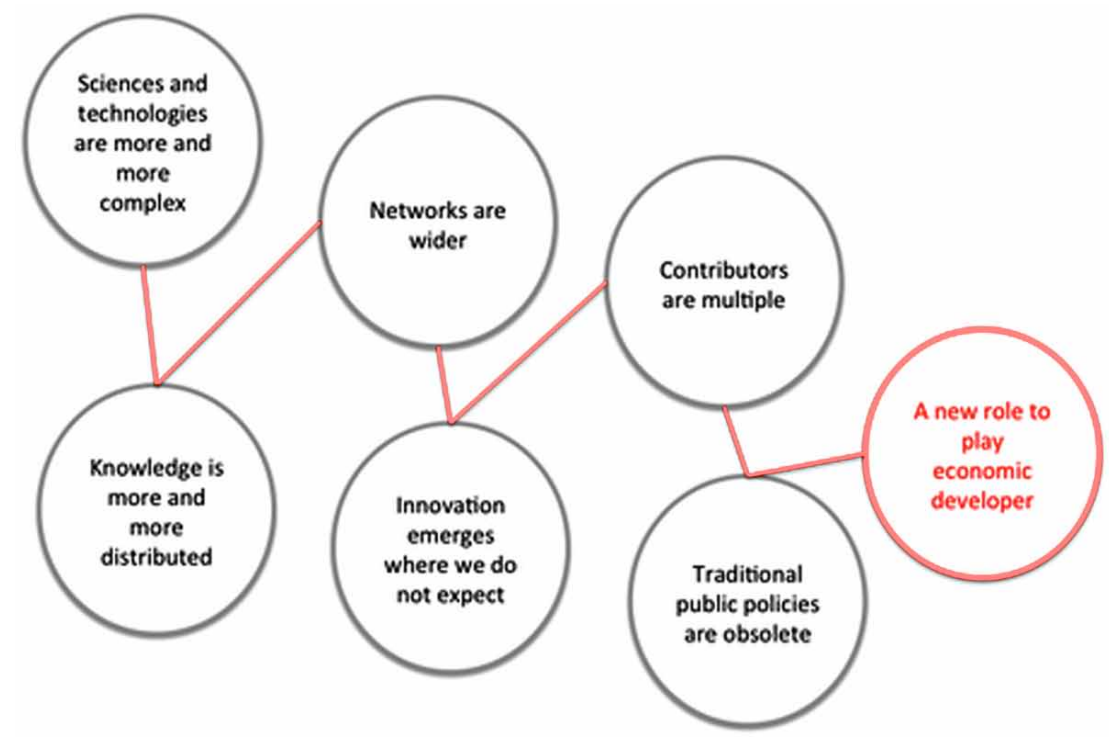

companies in order to support and accelerate tech transfer from universities to firm through valorization companies. Today, some of those companies, issued from VRQ, still exist but their business model needs to be re-invented.

Also, in this perspective, geographical proximity then becomes instrumental to accelerate this transfer. Territorial policies have been developed to help clusterization and tech transfer. In Montreal, scientific and technological parks have been developed such as Technoparc Montreal or Technopole Angus.

Nowadays, in what it is called the B perspective, no one can doubt that science and technologies are more and more complex. As a result, knowledge is also more distributed which means that people need wider networks to embrace specificities of their domain. Networks also become more heterogeneous and contributors are multiple. Thus, networks perspectives appear, bringing practitioners to include ecosystemic option in their strategies. Figure 2 offers a synthetic overview of this complexification process.

Von Hippel $(1986,2005)$ was one of the first to highlight the demand side of innovation, where some users can be very contributive to innovation process. Leadusers are defined by Von Hippel as «users that are engaged in developing or modifying products». They are actually 10 to 40 percent of users. Moreover, several studies have shown that many of the innovations made by lead users are «judged to be commercially attractive or have actually been commercialized by manufacturers». With lead users as contributors to the innovation process come to wider the networks involved in this process. So, it is important to understand how those networks structured to support hi-tech sectors such as biotechs. 
With the works of Cooke (2007a, 2007b) on Regional Innovation System (RIS), there is classification on the structure of the network. How its governance is structure and the source of innovation. It has been demonstrated that initial conditions and path dependency are important in the development of RIS and then of regional innovation. In other words, innovation paths are clearly determined by social and territorial construction: the structure of the network.

Because tools for innovation support on the demand side are not so well defined, innovation support emphasized strategies in a supplier view. For example, in the life science sectors, it aims to put right conditions in place to help entrepreneurs to have competitive advantage.

Quebec had developed a strategy regarding patents in the pharmaceutics sector and their duration. But, in the 00', the biotech revolutions echoed to be a solution for pharmaceuticals to reload the potential research on new cure.

In economic development and entrepreneurial support, the ecosytemic premises of innovation appeared with the work of Porter (1998, 2001). At the beginning Porter worked at the national level, then adapted his diamond shape model to the regional level (Porter 1998, 2001). The era of clusters as a management and decision tool came into place. Cities, all around the world have put in place innovation strategies consistent with the geographic concentration of firms in selected industrial sectors. Whereas, Marshall-Arrow-Romer (MAR) industrial districts brought innovation with a concentration of industries in the same field and end-up with monopolistic equilibrium, in the Porter's clusters, innovation occurs because of a simulation process engaged under the rules of competition. In the Porter vision, innovation began to be a complex process where suppliers, customers, and related industries work hand in hand to reach a dominant position on the market.

Montreal was no exception and the biotech cluster was one of the first, which has been brought to life back in the 00'. InVivo (the cluster secretary) is now at the crossroad and tries to help manufacturers and entrepreneurs to build a new pipeline of products and energize a new round of development. The idea is to enhance business model from a chemistry model to a biotech model, based only on the market offer to a model, which also support the demand side (users). Until now, it should be underline the quite good performance of the InVivo cluster. But since a few years, the industry, as well as the InVivo needs to redefine their model.

This need come from the changing business model in pharmaceutical industry, which implies a will of a change in the way biotech clusters support their members, but also from different initiatives on the demand side of innovation which is promising for supporting innovation even in the biotechs sector.

The reality is that innovation process and entrepreneurship support are two-fold. First, it depends on the supply side of entrepreneurs (intellectual property, funding, counselling, etc.) and on the demand side, which include users. In history then, 


\section{A New Tool for Supporting Innovation in Biotech Co-Innovation}

most of public policies and support was designed to help manufacturer in capturing innovation coming from research lab. But, many sociologists have stressed the importance of the network and the social fabric for the diffusion and the acceptance of innovation through society.

In regards of the Von Hippel' (1986) seminal work a new source of innovation has been pinpointed: the users. Chesbrough shown that the management of intellectual properties tend also to change. His now well-known open innovation concept brought the idea to a proactive intellectual property (IP) management. The way companies can benefit of research from others firms (even competitive ones) or how they can capitalize on their own research or IP. Subsequently, open innovation is about bringing idea into the company coming from anywhere. It is about collective intelligence and the way it could help entrepreneurs to boost their own innovation process.

Most recently, some different strategies, based on the demand side of innovation, are developed as per NEOMED project in Montréal. The NEOMED Institute «is a response to the changing pharmaceutic's $R \& D$ business model.

In view of the considerable gap between basic research and the commercialization of new drugs, we seek to create a bridge. It offers several facilities based on collaboration, creativity and innovation.

But, in the perspective of the demand side of innovation, this article explores a way to put the exercise of the NEOMED project-like a step further. It proposes a way to include users and new forms of entrepreneurship (Frangioni, 2015) in the support of innovation using these enriched communities as the engine of innovation. In fact, despite researches at the academic level, few works have been done to integrated, in one hand this new source of innovation (users) in the toolbox of economic developers, especially in the biotechs sector and, in the other hand to understand and structure the demand side to foster innovation.

\section{Highlight 1: The Fold-It Experiment}

Created by various departments and labs from the University of Washington, Fold-it explores the process by which living beings create the primary structure of proteins. The protein biosynthesis is reasonably well understood, as is the means by which proteins are encoded as DNA. Determining how the primary structure of a protein turns into a functioning three-dimensional structure - how the molecule "folds" is more difficult; the general process is known, but predicting protein structures is computationally demanding - gameforchange.org (2015).

The serious game Fold-it was created to accelerate research on proteomics and therefore research on human health. In three weeks, with the collective intelligence of the players, Fold-it has determined the three-dimensional shape of the protease 
that was involved in the spread of the AIDS virus in monkeys. Feat that had not been done after 10 years of research in scientific laboratories. Contributors to the game are both researchers in biology, medicine, but also designers, students, etc. Obviously, this development allows now developing experimental therapeutic in struggle against the AIDS virus in humans.

\section{A NEW ROLE FOR ECONOMIC DEVELOPER: CO-INNOVATION}

One question is still wide open, how economic developer could help to foster innovation, regarding the demand side of innovation process? The objective is not to wipe out the tools on the supply side of innovation, but to add new way of supporting innovation including users. In fact, we can sum-up the two side of innovation as two different, but complementary perspectives.

With a research on economic developers needs and tools in Quebec and France, the author has developed an intervention model for economic developers who want to integrate in their practice the co-innovation principle. The model is not a general model, but instead a model at the meso-economic level, which aim is to foster coinnovation as a tool, which complement existing one.

Stars represent specific actions of economic developer (ED). From each relevant ecosystem, ED connects to several individuals from each of these ecosystems, which is the agent network. It should be noted that according to the theory of structural holes (Burt and Celotto, 1992), the agent must connect to networks that have few connections together.

Then, he can have a deeper and broader vision of the problems or needs that emerge in a given area. Moreover, the principles of co-innovation are to allow for diversity (of individuals, communities and sectors) in a form of proximity (both geographical, but also cognitive, social, organizational and institutional). The notion of in-between centrality is also important because the ED plays an intermediary role in the developed model.

With business intelligence, the agent identifies some related elements through its network (and thus relays with different ecosystems). He developed more links with some required network members to get a better understanding of these related elements. This step is a work of agitation and disturbance that runs the network and which can be problematic and needs.

The phase of agitation and disturbance is important where ED must identify problematic or sufficiently complex needs so they can create sufficient working voltage that leads to action. Furthermore, the different points of view, here diversity in proximity, accelerate and intensify the work of agitation and disturbance of the agent. At that stage, meaning for the community begins to appear and the agent 


\section{A New Tool for Supporting Innovation in Biotech Co-Innovation}

will work to integrate the concept of user to complete the perspective of technical experts, by the secular experts.

These issues and needs remain diffuse at this stage, and ED must conduct an intermediary step and innomediation. Here, he acts as an interface to structure the needs and problems, on one hand, and bring the best players in the ecosystem, on the other hand, based on sometimes divergent interests, which can work to the identification of a common solution. Here, the ED agent must begin formatting content for defining experimental axes and methodologies that will be involved.

Working with this structure, the agent is able to create intrapreneurial opportunities. These opportunities are those, which may lead to structuring projects carried by communities. In this context, the intrapreneurial characteristics of the agent are put to use: he must have a vision, build alliances and structure projects and be tenacious as the co-innovation projects are still unclear, the agent often encounters difficulties in his own organization, which is not necessarily familiar with the principles and methods of co-innovation.

In fact, at this stage the agent begins to offer and sell his project within its own organization (intrapreneur) as well as in the community (exopreneur). He must show determination, because he finds himself in competition with projects of his colleagues in a world where resources are scarce (public funding).

In the next step, the agent builds a community of interest in which he is also one of the stakeholders. The thus created community defines strategic projects that will allow the implementation of innovative solutions to the needs and issues identified beforehand. Structuring projects are intended to help structure new emerging areas of development, but with great potential. This requires the creation of co-creatives platforms and third-places that can be digital (crowdsourcing, for example) or attendance-based (learning circles, for example) or a combination of both (Living Labs, for example).

It is important here to note that the concept of third-place or platform is critical to the success of collaborative or co-creatives projects. Indeed, communities need to express themselves in a space that is facilitating and not identified to any specific stakeholder. Although these platforms and third places can be physical places, they can be virtual as long as collaboration and co-creation can be expressed. Thus, according to Simon (2014), it takes the concept of physical locations (places) and semantic spaces (spaces) in which co-innovation can be expressed.

Note that this part of the process is represented in Figure 3 by circles, in order to show the dynamic mechanism. The constitution of solutions in innovative projects can itself create a feedback loop that leads to the identification of new needs and new issues, creating an additional iterative loop. However, the concept of animation is essential for innovative solutions to emerge and maintain the interest of participants in the community throughout the process. The animation is done through collabora- 
Figure 3. Intervention model for economic developers in a co-innovation context

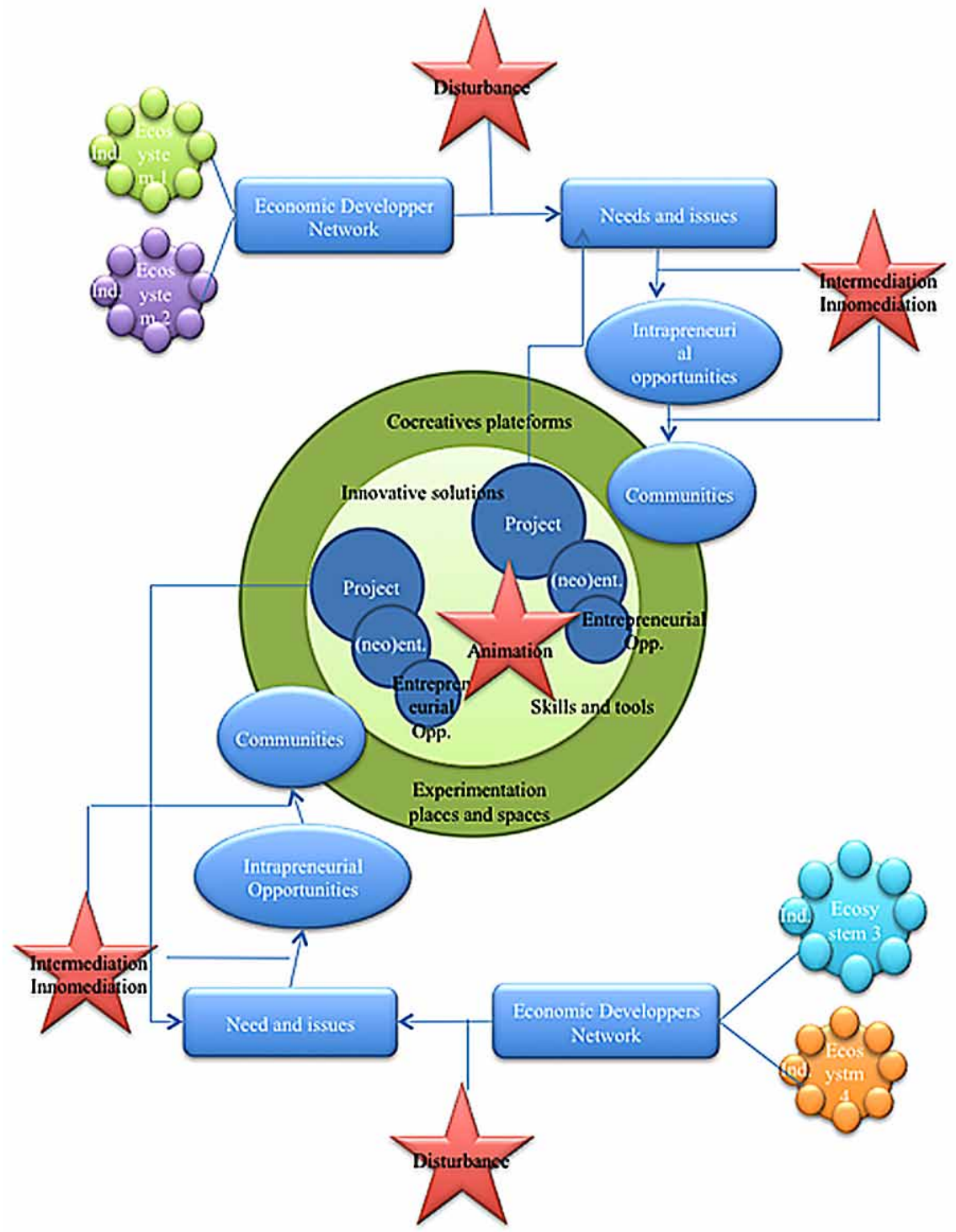

tive and co-creative tools. The choice depends on the state and the objectives of the emerging projects.

The animation requires an in depth knowledge of the sector and members of the communities from the facilitator. Financial people often see this task as ancillary in platform or to third place, while it is at the heart of the success of this kind of strategy.

The identification of innovative solutions creates entrepreneurial opportunities that can be seized by entrepreneurs. Entrepreneurial opportunities can come from structuring projects in which they participate directly or indirectly over the business 


\section{A New Tool for Supporting Innovation in Biotech Co-Innovation}

serendipity that is created in co-creative platforms and third-places. Furthermore, the development of entrepreneurial opportunities is built around a real market with real users that can serve as core to developing a community of users and customers, which can also improve along the way. Moreover, the use of tools and methodologies, and methods of co- innovation processes and results in negotiated rather than consensual solutions. The difference between negotiated and consensual lays here in the fact that in the first, stakeholders build their product or service by adding concepts related to common needs, in the second, the notion of consensuality takes a subtraction character. Indeed, for the consensual solution forms, one has to drop items that seem less important during the process.

Finally, the community comes to the end of a product or service that is found to be the lowest common denominator. In other words, the product or service does not really please anyone, but it does not displease to anyone also. In contrast, in the negotiated approach, the development of the product or service is done on an incremental basis. Thus, people constantly add to the initial idea, to reach the highest common denominator in some way. Moreover, when these spaces are real physical spaces as creative hubs, co-working spaces such gains are increasingly important as the pooling of business solutions is growing.

Ultimately, the role of the ED is twofold. It is targeted through certain actions that should be implemented, firstly to define needs or problems, to bring together communities that will structure projects and, secondly, to have a continuous action in relationships with his various networks. Although ED is a network agent, the fundamental difference that can be noted compared to more traditional methods lies in the locus of governance and participation, according to the principles of collaboration and co-creation. Moreover, when these spaces are real physical spaces as creative hubs, co-working spaces and such gains are increasingly important as the pooling of business solutions is growing.

As the complexity of knowledge is increasing, the ED needs to take more and more collaborative and co-creative posture and in the meantime learns the adoption of collaborative and co-creative tools for which he is ill informed or ill-equipped. The intervention model is a response to this lack of knowledge.

Some other elements are also to be considered, such as the stage of development of innovative solutions. At the pre-competitive stage, for example, a more open culture (especially with recent examples in biotechnology, traditionally closed culture and based on the management of intellectual property) can be integrated even in sectors that tend to close. However, in competitive phases, which are the formalization of a marketable product, there is a more closed approach.

The ED should also have a good read of the industry in which it wishes to intervene and when the procedure is done. In the case where innovative solutions are not mature, one must wonder about the fact whether the uses are known or not. 
In cases where technologies are not mature and uses are unknown, the co-creative technics should be promoted in order to reveal and determined the type of innovative solutions to be developed. This could be done by the use of realistic scenario in which users are deeply involved.

This can be illustrated by the example of the Living Lab SAT / Sainte-Justine where innovative solutions are relatively mature (3D immersive spaces, creating therapeutic avatars for children with serious illnesses - cancer - or disabilities autism - by example), but the uses are little known: how to improve therapeutic techniques using 3D environments? How customers (children, parents, caregivers, etc.) can target use appropriate these new treatment spaces? Otherwise, if innovative solutions are mature and known uses, then the ED officer should opt for more traditional support for entrepreneurship: advice, support for financing, real estate, if any. But, it may guide communities towards some elements of collaboration and co-creation.

In the case of biotech sector, some technologies are more mature whereas some other needs to gain in maturity. In the meantime, uses are sometimes well defined, whereas some need also to be refined. This is why I insist, particularly in this sector, in the complementary use of the perspective A and B in the support of innovation by ED agent. The key is not to replace traditional methods by collaborative and co-creative methods but more precisely define how and when use either of the methods properly.

\section{FUTURE RESEARCH DIRECTIONS}

The tools of co-innovation support compliant with the new intervention model developed in this book chapter should be fully developed for the biotech sector. An action research should be put in place to better understand the specificities of the sector to implement a strategy build around co-innovation in regards of the specific problematic of this sector. The model developed here should be also tested and improved.

\section{CONCLUSION}

This paper aims to define a model in order to complement the existing tools for ED agent in order to support innovation and entrepreneurship. It underlines the importance of the «demand side» in the innovation process. The co-innovation tools as platform or third-place is are instrumental to foster new source of innovation. 


\section{A New Tool for Supporting Innovation in Biotech Co-Innovation}

Of course, this model should be applied differently regarding the particularity of different sectors. The ED should have an in-depth knowledge of the sector, but also be connected to different ecosystem in order to develop heterogeneous communities and help the to support entrepreneurship in the biotech sector. One of the key element to understand in the biotech sector, is the degree of maturity of the technologies. Use of traditional method to support innovation should be put in perspective with the degree of maturity of the technologies and the knowledge on uses.

More research should be done to improve the model and a toolbox (guidelines of co-innovation tools) for ED is currently under development.

\section{REFERENCES}

Burt, R., \& Celotto, N. (1992). The Network Structure of Management Roles in a Large Matrix Firm. Evaluation and Program Planning, 15(3), 303-326. doi:10.1016/0149-7189(92)90095-C

Cohendet, P., Roberts, J \& Simon, L. (2010). Créer, implanter et gérer des communautés de pratique. Gestion, 4(35), 31-35.

Cooke, P. (2007a). To Construct Regional Advantage from Innovation Systems, First Build Policy Platforms. European Planning Studies, 15(2), 179-194. doi:10.1080/09654310601078671

Cooke, P. (2007b). Regional Innovation, Entrepreneurship and Talents Systems. International Journal of Entrepreneurship and Innovation Management, 7(2/3/4/5), 117-139. doi:10.1504/IJEIM.2007.012878

Frangioni, M. (2015). Un nouveau modèle de développement économique (DÉ) par l'innovation: la co-innovation, l'entrepreneuriat technologique et le rôle des agents de DÉ. [Thèse de doctorat en administration des affaires]. Université de Sherbrooke.

Granovetter, M. S. (1973). The Strength of Weak Ties. American Journal of Sociology, 76(6), 1360-1380. doi:10.1086/225469

Lemieux, V. (1976, May-August). L'articulation des réseaux[Québec]. Recherches Sociographiques, 17(2), 247-260. doi:10.7202/055716ar

Lemieux, V., \& Ouimet, M. (2006). L'analyse structurale des réseaux sociaux, Québec et Bruxelles. Les Presses de l'Université Laval et De Boeck Université, 2004.

Porter, M. E. (1998). Clusters and the New Economics of Competition. Harvard Business Review, 76(6), 77. PMID:10187248 
Porter, M.E. (2001). Cluster of Innovation: Regional Foundation of U.S. Competitiveness.

Von Hippel, E. (1986). Lead users: a Source of Novel Product Concepts. Management Science, 32(7), 691.

Von Hippel, E. (2005). Democratizing innovation. Cambridge, Massachusetts: The MIT Press. 
A Database for Progressive Information Science and Technology Resea

\section{Maximize Your Library's Book Collectic}

Invest in IGI Global's InfoSci-Books database and gain access ts hundreds of reference books at a fraction of their individual list pric

The InfoSci-Books database offers unlimited simultaneous users the ability to precisely return search results through more than 68,000 full-t chapters from nearly 3,000 reference books in the following academic researc

Business \& Management Information Science \& Technology • Computer Science \& Information Technolos Educational Science \& Technology • Engineering Science \& Technology • Environmental Science \& Techno Government Science \& Technology $\bullet$ Library Information Science \& Technology $\bullet$ Media \& Communication Science $\varepsilon$ Medical, Healthcare \& Life Science \& Technology $\bullet$ Security \& Forensic Science \& Technology $\bullet$ Social Sciences \& Or

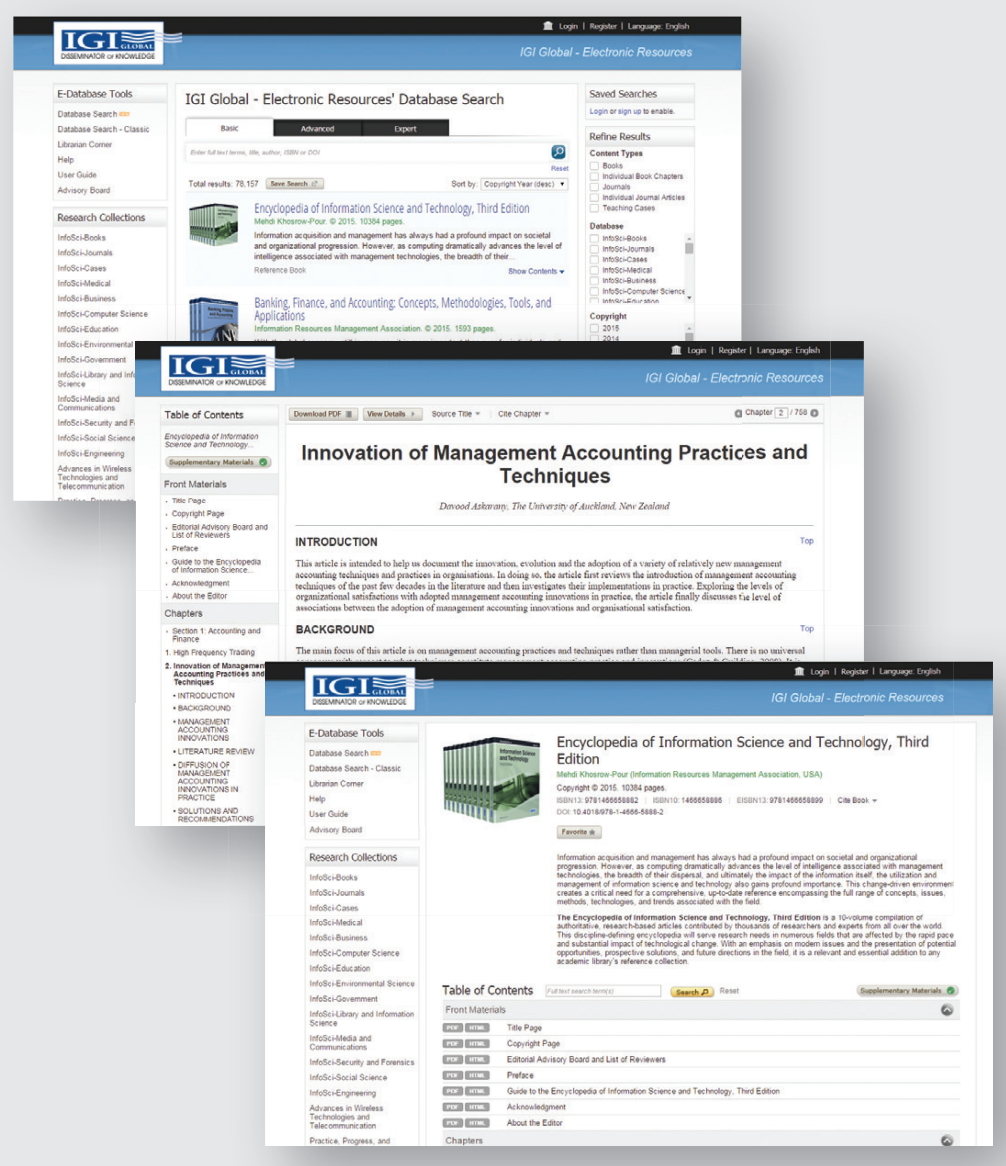

\section{Peer-Reviewed Content:}

- Cutting-edge research

- No embargoes

- Scholarly and professio

- Interdisciplinary

\section{Award-Winning Platform:}

- Unlimited simultaneous

- Full-text in XML and PC

- Advanced search engin

- No DRM

\section{Librarian-Frienc}

- Free MARC records

- Discovery services

- COUNTER4/SUSHI col

- Training available

\section{To find out more or request a free trial, visit: www.igi-global.com/eresources}

